\title{
Overseas travel health SeMinaR
}

Greg Stewart, Medical Officer of Health

Kerry Chant, Public Health Officer, South Western

Sydney Area Health Service Public Health Unit

\section{SUMMARY}

Public Health Unit staff are often required to give advice to people planning to travel overseas. The South Western Sydney Area Health Service Public Health Unit organised a seminar to canvass issues that recur in giving travel health advice. This article covers discussions about topics such as malaria and other mosquito-borne diseases, food and waterborne diseases, sexually transmissible diseases, rabies, meningococcal meningitis and vaccinations.

$\mathrm{T}$ hose of us who provide telephone advice to overseas travellers know it is sometimes difficult, sometimes amusing, sometimes an encumbrance on our heavy workload, but always a satisfying means of maintaining contact with the people of the Areas/Districts we serve.

It is not easy to provide concise and accurate advice to overseas travellers over the phone and indeed there is a view that such advice should be given only at a one-to-one consultation. But we believe the advice that can be given about food and water precautions, measures to prevent mosquito bites and recommended vaccinations is a useful starting point for those who contact us. In common with other Public Health Units, we always emphasise that more detailed advice, prescription of vaccines and anti-malaria tablets must be undertaken by the caller's local doctor, who will have detailed knowledge of his/her medical history. For those with complex itineraries, we often recommend attendance at a travel health practice.

Several difficult issues recur in giving travel health advice and advice can vary depending on the person, time of travel and place to be visited. For this reason, the South Western Sydney Area Health Service (SWSAHS) Public Health Unit organised an overseas travel health advice seminar for PHU staff and private practitioners interested in the providing of care to overseas travellers. The seminar was held in January 1992.

SWSAHS has several experts in international health close at hand. Professor Karl Rieckmann, of the Australian Army's Malaria Research Unit, is based at Ingleburn. Professor Rosemary Munro, Director of Microbiology, South Western Area Pathology Service, is based on the Liverpool campus. The Commonwealth Government's Communicable Diseases Adviser, Dr Robert Hall, is located a little further south. The only speaker at the conference who had to travel any distance was Dr Mark Ferson, Director of the Eastern Sydney Public Health Unit.

The four speakers provided seminar participants with up-todate advice about overseas travel issues. Their contributions generated much discussion, a summary of which follows.

\section{MALARIA}

Professor Rieckmann gave an update on malaria around the world. He emphasised the increasing resistance to anti-malarials, in particular in northern Thailand and the
Thai-Burmese border. He also emphasised the necessity of measures to prevent mosquito bites, including use of DEET-containing repellents, mosquito netting, and avoidance of situations which may result in mosquito bites.

The consensus of the seminar was that the Commonwealth Government booklet, Health Information for International Travel, provided the most up-to-date and rational approach to malaria chemoprophylaxis. For travellers with complicated travel plans, it was agreed that a personal consultation with an expert in international health would be advisable.

\section{OTHER MOSQUITO-BORNE DISEASES}

Dr Hall spoke about other mosquito-borne diseases such as dengue fever, Japanese encephalitis and yellow fever. Like Professor Reickmann, he emphasised the importance of measures to prevent mosquito bites. He outlined Commonwealth Government policy in relation to yellow fever, i.e. restrictions on people entering Australia from infected areas, as defined in the Weekly Epidemiological Report. The restrictions are much more stringent for people travelling north of Brisbane because of the potential for transmission of the disease.

In relation to Japanese encephalitis, Dr Hall said there had been four serious reactions to the vaccine since he had been in charge of approving its use (about 1,000 doses were approved in this period). For this reason, it is no longer available for travellers to areas where Japanese encephalitis is endemic.

\section{FOOD AND WATERBORNE DISEASES}

Dr Ferson summarised current issues in relation to food and waterborne diseases, in particular hepatitis A and typhoid. It was noted that a vaccine against hepatitis $\mathrm{A}$ will soon be available in Australia. [Editorial Note: the vaccine was released in July this year.] It was agreed this should be used in preference to Human Normal Immunoglobulin (HNIG). The issue of serological testing before administration of HNIG (or in the future hepatitis A vaccine) was discussed and it was agreed this would be worthwhile, particularly for those who go overseas frequently. The older the traveller, the more reason there is for serological testing, as the proportion of people with antibodies increases with age.

Seminar participants agreed the oral typhoid vaccine is preferable to the injectable vaccine. The issue of booster doses for the oral vaccine was raised. It was agreed that the manufacturer's guidelines for booster doses should be followed. Concerns about non-compliance with the oral vaccine were raised and this problem should be borne in mind when prescribing the oral typhoid vaccine.

There was no consensus about the use of cholera vaccine. It was recognised that the vaccine has low efficacy and short duration. Nevertheless, because of the El Tor epidemic, there were reports that travellers to endemic areas were being required to have on-the-spot vaccination if they did not have a current vaccination certificate. Some seminar participants recommended a single shot of cholera vaccine when still in Australia to avoid the possibility of a less than hygienic injection overseas. 


\section{Overseas travel health seminar}

$\checkmark$ Continued from page 89

It was suggested that since overseas authorities who adopt the above approach are basically interested in documentary proof of vaccination, such documentation could be provided without the vaccine being given. There was a difference of opinion among seminar participants about this approach. Dr Hall emphasised that no country officially requires cholera vaccination or proof of same.

\section{RABIES}

It was agreed that advice about avoidance of domestic and wild animals was not given frequently enough. Professor Munro emphasised that all travellers should be advised to avoid wild and domestic animals (although domestic animals are considered to be safe in many developed countries). Long-term visitors to rabies-infected countries, and those with potential vocational exposure, should be considered for pre-exposure prophylaxis. There was no consensus about prophylaxis for "back-packers".

\section{MENINGOCOCCAL MENINGITIS}

Dr Hall emphasised that epidemics of meningococcal meningitis occur frequently in some parts of the world.

\section{PUBLIC HEALTH EDITORIAL STAFF}

The Bulletin's editorial advisory panel is as follows: Dr Sue Morey, Chief Health Officer, Public Health Division, NSW Health Department; Professor Stephen Leeder, Director, Department of Community Medicine, Westmead Hospital; Professor Geoffrey Berry, Head, Department of Public Health, University of Sydney; Dr Christine Bennett, General Manager, Royal Hospital for Women; Dr Michael Frommer, Deputy Director, Epidemiology and Health Services Evaluation Branch, NSW Health Department; Ms Jane Hall, Director, Centre for Health Economics Research and Evaluation; and Mr Michael Ward, Manager, Health Promotion Unit.

The editor is Dr George Rubin, Director, Epidemiology and Health Services Evaluation Branch, NSW Health Department.

The Bulletin aims to provide its readers with population health data and information to motivate effective public health action.

Articles, news and comments should be 1,000 words or less in length and include a summary of the key points to be made in the first paragraph. Please submit items in hard copy and on diskette, preferably using WordPerfect 5.1, to the editor, Public Health Bulletin, Locked Mail Bag 961, North Sydney 2059. Facsimile (02) 3919232.

Design - Health Public Affairs Unit, NSW Health Department. Suggestions for improving the content and format of the Bulletin are most welcome.

Please contact your local Public Health Unit to obtain copies of the NSW Public Health Bulletin.
Details of areas with recent epidemics, and those for whom vaccination is recommended, can be found in Health Information for International Travel.

\section{ROUTINE VACCINATIONS}

Seminar participants agreed that all travellers should be advised to update their routine vaccinations. In the case of tetanus and diphtheria, this should be as a booster dose of ADT every 10 years. Travellers to developing countries should be advised to have a booster dose of polio vaccine, if one has not been given in the previous 10 years. Oral polio vaccine (OPV) should be used, except in those cases where the well-described contraindications mean that killed vaccine is indicated. The rare complication of OPV-induced polio was discussed. However, it was agreed that the benefit of a booster dose of vaccine outweighed this risk.

\section{SEXUALLY TRANSMISSIBLE DISEASES}

Seminar participants agreed that brief (or in occasional cases more detailed) advice about the possibility of acquiring sexually transmissible diseases, including hepatitis B and HIV, was a valuable part of provision of travel health advice and should be given to most travellers.

\section{OTHER ISSUES}

Participants agreed that a "cookbook" approach to overseas travel health advice is inappropriate. It was also agreed that electronic cookbooks are not useful unless the user has up-to-date knowledge about overseas travel health issues.

There was discussion about whether telephone advice should be followed up by written advice, perhaps including some fact sheets. It was noted that Health Information for International Travel contains several very useful fact sheets. The consensus was that PHUs which provide overseas travel advice should follow up this advice with a written record of the advice given, accompanied by fact sheets.

\section{CONCLUSION}

Public Health Units have an important role to play in provision of travel health advice as we often have more up-to-date information than many GPs. While we always emphasise the importance of a formal consultation with a doctor, the information we can provide is a useful starting point for travellers.

\section{INFORMATION SOURCES}

Health Information for International Travel. 3rd edition 1991. Commonwealth Department of Health, Housing and Community Services.

International Travel and Health - Vaccination Requirements and Health Advice. Annual editions. World Health Organisation (obtainable from Hunter Publications, PO Box 404, Abbotsford Vic. 3067). Travel Bugs - CSL's Country by Country Guide to International Travel Immunisation. 3rd edition. Commonwealth Serum Laboratories. Health Information for International Travel. Annual editions. US Department of Health and Human Services, Public Health Service. Immunisation Procedures. 4th edition 1991. NHMRC.

Travel Health Info Line (Commonwealth Department of Health, Housing and Community Services) phone (06) 2697815 . (For up-to-date information about yellow fever-infected areas phone (06) 269 7816.) 